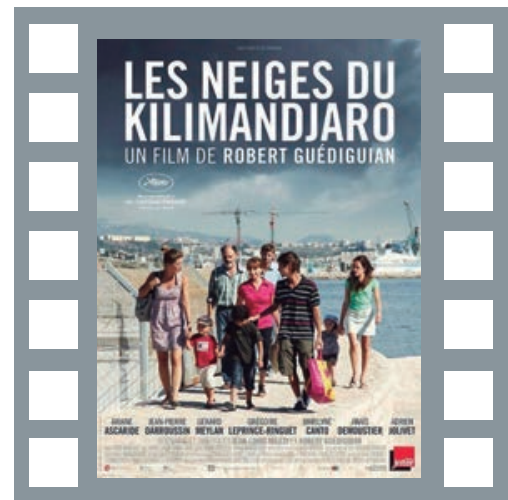

\section{ficha têcnica}

Título original: Les neiges du Kilimandjaro

Nacionalidad: Francia

Dirección: Robert Guédiguian

Guion: Robert Guédiguian, Jean-Louis Milesi (Inspirado en el poema de Victor Hugo, Les pauvres gens)

Productora: Agat Films \& Cie / France 3 Cinéma / Canal+ / CinéCinéma / France Télévision / Cinémage 5 / Banque Postale Image 4 / Soficinéma 7/Agat-Films \& Cie / Ex Nihito / France 3 Cinéma

Año: 2011

Interpretación: Ariane Ascaride (Marie-Claire), Jean-Pierre Darroussin (Michel), Gérard Meylan (Raoul), Marilyne Canto (Denise), Grégoire Leprince-Ringuet (Christophe), Anaïs Demoustier (Flo), Julie-Marie Parmentier (Agnès), Adrien Jolivet (Gilles), Robinson Stévenin (comisario), Karole Rocher (madre de Christophe), Pierre Niney (Waiter, camarero), Jean-Baptiste Fonk (Martín), Emilie Piponnier (Maryse), Raphaël Hidrot (Jeannot), Jean Loubatiè (Jules

Música: Pascal Mayer

Fotografía: Pierre Milon

Género: Drama, socia

Duración: 107 minutos

Trailer: https://www.youtube.com/watch?v=4KMZlqA6tU0

Web oficial: http://www.golem.es/lasnievesdelkilimanjaro/

Premios: 2011- Premio Lux de Cine del Parlamento Europeo. Premios César nominada a mejor actriz Ariane Ascaride. Festival de Cannes, Premio del Público. Festival de Valladolid-Seminci: Espiga de Plata, Premio de Público. VI Festival de Cine Inédito de Mérida, Premio del Público.

\title{
Las nieves del Kilimanjaro
}

lógica que teje la trama de los sucesos. Alfonso López Quintás

María Ángeles Almacellas Bernadó

y Carmen Pereira Domínguez

mangeles.almacellas@gmail.com y mcdguez@uvigo.es

\section{La historia}

Michel Marteron, de unos cincuenta años, trabaja en los astilleros de Marsella y es representante sindical de los trabajadores. Como consecuencia de la crisis financiera, su empresa se ve obligada a despedir a veinte personas y Marteron pierde su trabajo. Quedarse en paro supone una contrariedad, pero Michel y su esposa Marie-Claire van a poder seguir viviendo sin demasiados apuros. Ni tan siquiera les impide celebrar sus 30 años de feliz matrimonio, rodeados de sus hijos, nietos y un gran número de amigos y compañeros de trabajo. Como regalo de aniversario de parte de todos, reciben un viaje al Kilimanjaro.

Pero su felicidad y sus proyectos se ven frustrados una noche en que dos hombres armados y enmascarados entran en su domicilio, les agreden violentamente y les roban el dinero y los pasajes. Denuncian el atraco a la policía, esperando que encuentren a los culpables y se haga justicia. Cuando Michel y su esposa descubren quién fue el agresor y cuáles son sus circunstancias, sus convicciones y su sentido ético inquebrantable son puestos a prueba.

\section{Temas}

Desigualdad de género

Doctrina Social de la Iglesia

Dramas del paro

Exclusión social

Familia

Jubilación

Infancia y juventud

Personas mayores y su cuidado

Trabajo y precariedad laboral

Violencia

\section{Valores}

Amor

Compromiso socia

Ética

Felicidad

Justicia social

Optimismo

Perdón

Solidaridad

Ternura

Vida

\section{(৫.) Antes de ver la película}

1. Reflexionamos sobre el valor de la justicia. ¿Qué significa ser justo? ¿Se puede considerar que alguien es justo por el mero hecho de no cometer ninguna injusticia, es decir, por tratar todas las realidades con el respeto debido? 0 ital vez ser justo implica no solo mantenerse en los límites de lo correcto, sino que supone colaborar activamente a que cada persona esté en condiciones de poder desarrollarse?

2. ¿Cuál es la labor de los sindicatos y de los representantes sindicales en una empresa? ¿Creéis que el sindicalismo actual atiende a las necesidades de la clase trabajadora?

3. ¿Qué es la Doctrina Social de la Iglesia (DSI)? Buscamos información sobre las actitudes que pide:

3.1. A los patronos respecto de los asalariados.

3.2. A los asalariados respecto de su trabajo.

4. Expresa tu opinión sobre la importancia de que los católicos conozcan la DSI y comprendan la importancia de aplicarla en la vida de cada uno. ¿Hasta dónde debería llegar el compromiso personal de cada persona respecto de los más desfavorecidos y necesitados?

5. Buscamos información y debatimos sobre el concepto de familia, origen, tipos, evolución. ¿Qué valores se inculcan desde la familia? ¿Cómo valoramos a la familia?

6. Nos informamos sobre el significado de cine social. Citamos y describimos muestras cinematográficas de este estilo. ¿Quiénes las dirigen?, ¿qué temáticas tratan? Y ¿qué valores resaltan? https:// es.wikipedia.org/wiki/Cine_social

7. Indagamos sobre Robert Guédiguian, director de la película que trataremos en esta guía, Las nieves del Kilimanjaro. https://es. wikipedia. org/wiki/Robert_Gu\%C3\%A9diguian

8. Nos documentamos sobre Marsella, una de las principales ciudades francesas, donde se rueda esta película. Una vez visto el filme dialogaremos sobre la preferencia del director por este lugar. 


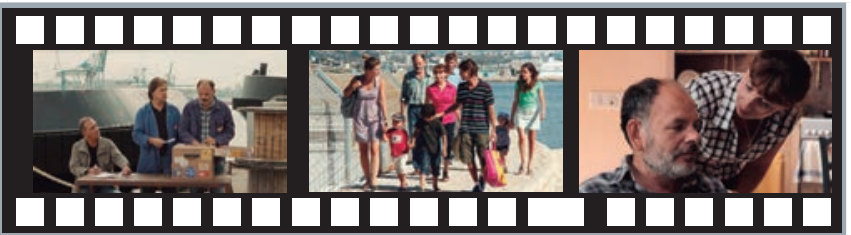

Conocemos a los protagonistas, Michel y Marie-Claire, en todos los ámbitos en los que establecen relaciones

1.1. En el trabajo: no se rigen por lo legal, sino por lo que ellos consideran ético.

Michel pone su número en la urna a pesar de no estar obligado por ser representante sindical (00:00:39-00:04:35).

Marie-Claire atiende a la señora que cuida sin ceñirse a horarios: puede irse antes, pero ella -y hasta Michel— están siempre disponibles (00:05:16-00:05:32 y 00:12:00-00:13:38).

1.2. En familia:

Han creado entre ellos un ámbito de amor, respeto y ayuda mutua.

Las relaciones con los hijos son entrañables. Siempre están dispuestos a ayudarlos (00:06:55-00:09:40).

1.3. Con amigos y compañeros:

Son personas honradas y bondadosas, que se han ganado el aprecio de todos (00:15:53-00:23:34).

\section{(2)}

Detonante del conflicto
1.1. Ambos cumplen rigurosamente con sus obligaciones, además, los dos están comprometidos personalmente. Michel se arriesga a quedarse sin trabajo por solidaridad con sus compañeros. MarieClaire trata con inmensa ternura a la señora para la que trabaja, más allá de sus estrictas obligaciones con las labores domésticas. ¿En qué idea de persona está fundamentada su código ético? ¿Cómo entienden ellos la responsabilidad en el trabajo? ¿Y cómo establecen las relaciones con su entorno?

Raoul censura a Michel por poner su nombre en la urna; la hija de la señora recrimina a Marie-Claire que se vaya antes de la hora convenida. Compara el código ético de esas dos personas, su sentido de responsabilidad en el trabajo y el modo de crear relaciones humanas con los principios básicos de Michel y Marie-Claire.

1.2. ¿Cuál es la realidad de matrimonio que encarnan los Marteron? ¿Qué actitud y qué virtudes han hecho que su amor haya perdurado tan vivo a través de los años? ¿Qué valores destacamos en Michel y Marie-Claire, entre ellos dos, y respecto de los hijos y los amigos?

1.3. ¿Por qué la gente de su entorno los aprecia? ¿Qué rasgos, nos parece, deben valorar en ellos para que se unan a la fiesta y al regalo incluso los que acaban de ser despedidos de la empresa?

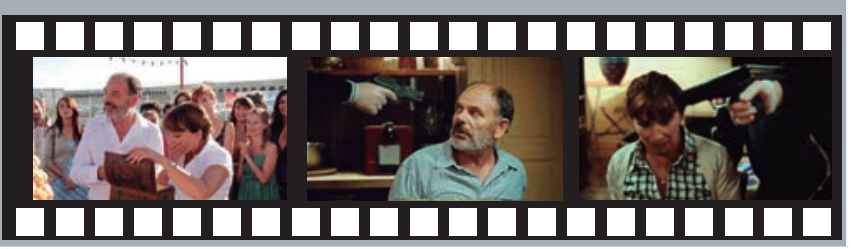

2.1. Su vida apacible, la ilusión de un gran viaje, todo es violentamente alterado por un atraco.

2.2. Vemos como, a partir de ese momento, todo se les viene abajo:

a. Del gozo de sentirse queridos pasan a la experiencia del odio y el maltrato.

b. De mirar a su entorno con cariño y deseo de ayudar pasan a la desconfianza de no saber quién puede agredirlos.

c. El viaje de símbolo de afecto respeto y reconocimiento de su compromiso generoso con los demás, se convierte, en boca del atracador, en un agrio reproche de falta de solidaridad.

2.1. En el asalto participan dos delincuentes. ¿Vemos algún rasgo que nos indique que uno de ellos es menos malvado que el otro?

2.2. Nos ponemos en lugar de las víctimas y nos planteamos cuál sería nuestra reacción. Pasado el susto, ¿qué sentimiento nos quedaría?, ¿qué esperaríamos que se hiciera con los culpables?

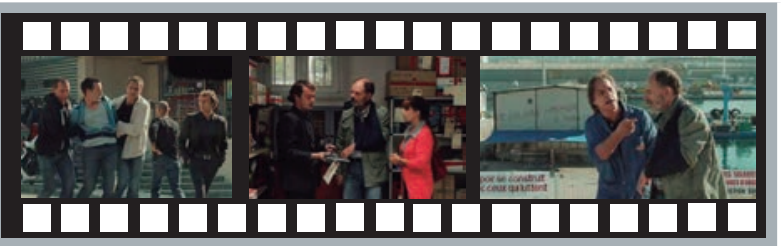

Michel y Marie-Claire tienen que reaccionar y decidir qué actitud deben adoptar

3.1. Michel tiene dos entrevistas muy tensas con Christophe, la primera, justo cuando este acaba de ser detenido (00:50:0000:52:08) y la siguiente cuando los Marteron ya han retirado la denuncia (01:24:43- 01:27:30). Christophe esgrime siempre los mismos argumentos mientras que Michel ha cambiado claramente de actitud.
3.1. En la primera entrevista con el detenido, ¿qué pensamos que le duele más a Michel, el dinero que le ha robado o los reproches de Christophe? ¿Qué le hace cambiar tan radicalmente de actitud? Ambos hablan de injusticia. Analizamos qué parte de razón pueden tener cada uno de ellos y averiguamos si están en contradicción o son dos ideas complementarias sobre la justicia. 
3.2. Los cinco personajes involucrados en el atraco lo viven de forma distinta:

a. Michel se siente víctima de una terrible injusticia (00:53:0600:53:40).

b. Marie-Claire está desconcertada y quiere entender al delincuente (00:59:58-01:00:33).

c. Raoul está tan enfadado que, más allá de la justicia, quiere venganza (00:56:01-00:56:33)

d. Denise está hundida totalmente (01:06:32-01:06:46).

e. Christophe Brunet se siente una víctima del sistema, siente que no tenía otra alternativa ante una injusticia social hacia él y sus hermanos (01:26:37-01:27:02).

3.3. A Michel y Marie-Claire la agresión les ha causado dolor físico y moral, pero no les ha dejado odio ni rencor. Son ecuánimes, no buscan venganza, solo quieren justicia y recuperar lo que es suyo. Lo que más les duele es haber sido tildados de personas egoístas e insolidarias, pues su actitud ha sido siempre generosa y comprometida con los demás. Una vez que recapacitan y juzgan a Christophe, su agresor, no por lo que ha hecho sino atendiendo a quién es, cambian radicalmente de actitud.

3.4. Cuando Michel y Marie-Claire consiguen superar el miedo y la cerrazón que les habían provocado la injusticia y el dolor sufridos, recobran su ser natural, solidario y bondadoso, y se esfuerzan por conocer la dura realidad de Christophe. Esto no significa indiferencia ante los actos reprobables que haya podido llevar a cabo. El atraco fue, sin duda, algo censurable y punible, pero ellos quieren entender a la persona, ser justos y no vengativos. En el momento en que conocen los motivos de por qué llevó a cabo el robo, comprenden que una situación extrema no justifica un delito, pero constituye un atenuante digno de tenerse en cuenta y así lograr sobreponerse a la triste vivencia.

3.5. Christophe que no solo perpetró el robo, sino que trató a las cuatro víctimas con crueldad. Tras su detención, en vez de mostrar arrepentimiento, los insulta y los denigra. Además rechaza la mano que se le tiende. Lo más fácil sería adoptar la actitud de Raoul y Denise: que obre la ley y el delincuente pague su delito como se merece. Pero Michel y Marie-Claire son personas generosas y cada uno de ellos por separado toma la misma iniciativa de responsabilizarse de los niños, que son las dos víctimas inocentes más desvalidas de toda la historia.

a. Marie-Claire asume la responsabilidad de los niños: primero cuida de ellos y finalmente se los llevará a casa (01:16:5001:17:51).

b. Michel va a llevar dinero a los niños para que puedan subsistir, pero una vez conocida la verdadera realidad de su situación, quiere también acogerlos (01:27:30-01:29:45).

c. La decisión está tomada por ambos (01:29:45-01:34:05). Han ido por distintos caminos, pero han llegado al mismo punto.
3.2. Sería importante llevar a cabo un juicio ético sobre cada personaje. Primero buscamos los motivos que avalan su actitud. Pero que algo sea lógicamente "explicable" no implica que sea "justificable", por tanto, conviene indagar si sus reacciones son correctas o reprobables. Describimos los diversos planos fílmicos utilizados.

3.3. ¿Veis a Christophe un ser desvalido que se desvive por mantener a dos niños, y que, de súbito, se ha visto despedido de la empresa, sin poder percibir ningún ingreso para cubrir las necesidades más elementales? La lucha personal de Michel y Marie-Claire es dramática. Esta situación altera las buenas relaciones entre ellos y les provoca tal desazón que los deja desorientados y profundamente desanimados. ¿Cuándo y por qué se recompone totalmente la armonía entre ellos? ¿Qué consecuencias podríamos extraer para nuestra propia vida?

3.4. Las circunstancias Ilevaron a Christophe a no ser más que un número en una urna, sin que nadie considerara que dos niños dependían exclusivamente de su salario para sobrevivir. Y ahora, con él en la cárcel, sus hermanos Jules y Martin, se han quedado sin familia y sin hogar. Para dos personas buenas, como Michel y Marie-Claire, esta es una injusticia y una agresión tan grave como la que ellos sufrieron.

Podríamos hacer un esfuerzo de imaginación y encarnarnos en un personaje, cada uno en aquel con cuya actitud se identifique mejor. Y, al hacerlo, cada cual tiene la posibilidad de cambiar la historia de su personaje. ¿Cómo se comportaría si estuviera en su lugar? ¿Por qué? ¿Qué consecuencias tendría su actuación?

3.5. Observamos el itinerario que sigue cada uno de los dos personajes protagonistas hasta llegar al mismo sitio. Al final parece que han recuperado su felicidad. ¿Por qué? Valoramos la interpretación de cada uno de los personajes.

Cuando Marie-Claire está con los niños dándoles la cena, sentados los tres ante el televisor, suena música religiosa, es un kyrie. Kyrie eleison significa Señor, ten piedad. ¿Qué sentido tiene esa música religiosa en una película que no hace ninguna alusión al hecho religioso? Expresamos cómo nos sentimos ante esta escena.

Podemos plantearnos por qué, cuando un ser humano vive incondicionalmente los grandes valores - como la bondad, el amor y la solidaridad - , queda situado en el umbral de la trascendencia. Traspasarlo o no es una decisión personal.

\section{Epílogo}

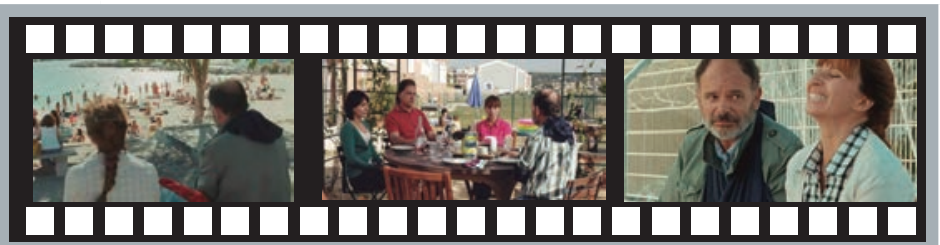

Reacciones de los demás ante la decisión de Michel y Marie-Claire

4.1. Los hijos reaccionan con mucho enfado, sin embargo, Raoul y Denise se solidarizan con la decisión de Michel y Marie-Clarie. "Nosotros hemos venido a deciros que eso sí se hace", les dicen. Es conmovedora esa escena en la terraza, haciendo una barbacoa con los niños. Cierra perfectamente la historia. (OrellanA, J., Almacellas, M. ${ }^{a}$ A., y Watt, N. (2019). Manual de crítica de cine. Madrid: CEU Ediciones).
4.1. Nos detenemos en las actitudes de los hijos y las de Raoul y Denise. Todos quieren el bien de Michel y Marie-Claire, pero sus puntos de vista son distintos. ¿Cómo explicaríamos las posturas de unos y otros? Valoramos, en su conjunto, toda esta escena. 
1. El título de la película, Las nieves del Kilimanjaro (Henry King, 1952), no tiene nada que ver con la película del mismo nombre y basada en la obra homónima de Ernest Hemingway.

En el caso del filme de Guédiguian, el título está sacado de una canción de Pascual Danel, cuyo estribillo simboliza el argumento de la película: en sus vidas felices se hará súbitamente de noche cuando ya tenían las nieves del Kilimanjaro al alcance de la vista. Sin embargo, ya no podrán llegar.

https://www.youtube.com/watch?v=Mf1vBzl6ei4

https://www.traduceletras.net/es/pascal-danel/kilimandjaro/404635/

2. Con una trama argumental distinta, el tema de la historia está inspirado en un poema de Víctor Hugo, Les pauvres gens, que comien- za justamente con las palabras // est nuit, "Es de noche", como en la canción. En el poema de Víctor Hugo, la esposa de un humilde pescador espera angustiada el regreso de su marido. Son muy pobres y él arriesga cada día su vida para poder llevar el sustento a su familia. Pero la mujer se conmueve hasta tal punto cuando comprueba que una viuda que vivía en la miseria acaba de fallecer, que decide acoger a los dos huérfanos que han quedado solos y desamparados. Como en la historia de Michel y Marie-Claire, cuando el marido le plantea a su mujer que se lleven los niños a su casa, ella se los muestra tras una cortina. Los protagonistas del poema y de la película, tienen una grandeza de espíritu admirable y, a pesar de sus circunstancias penosas y de no poder llegar a "las nieves del Kilimanjaro", están abiertos a la generosidad incondicional.

\section{Actividades de enperiencia, reflekión y acción en común}

1. Nos informamos y debatimos sobre la crisis económica española de 2008:

1.1. ¿Cómo surgió y qué consecuencias tuvo?

1.2. Muchas familias se quedaron sin trabajo y sin recursos. ¿Fueron suficientes los servicios sociales para apoyarlas?

1.3. Y los católicos, ¿cómo dieron respuesta a esa realidad? ¿Practicaron los valores de la generosidad y la solidaridad?

2. Investigamos sobre Cáritas, qué es, de quién depende, cómo funciona. .

2.1. Recabamos datos de la labor de Cáritas en los años de la recesión.

2.2. Comparamos las cifras de ese tiempo con las de los años inmediatamente anteriores.

2.3. ¿Cuál es el valor de la labor de Cáritas? Pensamos que es necesaria o que solo los servicios sociales son suficientes.

https://www.caritas.es/quienes-somos/conoce-caritas/

3. Deliberamos sobre:

3.1. El valor de las normas como cauce para poder moverse con auténtica libertad (por ejemplo, respetar las reglas del fútbol o del ajedrez para poder ser un auténtico buen jugador).

3.2. Cómo no siempre coincide lo legal y lo ético (por ejemplo, no son éticamente buenas las leyes que permiten el aborto, la eugenesia, la eutanasia...).

3.3. Qué actitud debemos adoptar en caso de conflicto entre lo legal y la propia conciencia.

4. Analizamos la estructura del relato de Las nieves del Kilimanjaro: en la primera escena del filme, después de que haya salido el nombre de Michel para la lista de los que iban a ser despedidos,
Raoul protesta por lo que él considera un exceso de corrección de su cuñado, pero, en el fondo, lo admira por su integridad ética y su coherencia en el obrar $y$, finalmente, le da un abrazo lleno de amistad y respeto. Una escena idéntica cierra la película: a pesar de estar en desacuerdo con la decisión de asumir la responsabilidad de ocuparse de Jules y Martin, Raoul y Denise se solidarizan con los Marteron y ambos cuñados se funden de nuevo en un entrañable abrazo.

La estructura de la narración está enmarcada por dos abrazos de afecto y admiración por la grandeza de espíritu de Michel y MarieClaire:

Primer abrazo de Raoul y Michel:

4.1. Planteamiento:

- Vida de los personajes antes del conflicto.

- Detonante del conflicto.

4.2. Núcleo:

- Reacciones al ataque.

- Discernimiento.

4.3. Desenlace:

- Decisión final.

Segundo abrazo de Raoul y Michel.

5. Finalmente, leemos a modo personal, la siguiente entrevista realizada al director de esta película, Robert Guédiguian. Después, comentaremos conjuntamente sus ideas más destacadas. http://www.abcguionistas.com/noticias/entrevistas/robert-guediguian-habla-sobre-las-nieves-del-kilimanjaro.html 